\title{
Visibility and Ceiling Nowcasting Using Artificial Intelligence Techniques for Aviation Applications
}

\author{
Fabricio Magalhães Cordeiro ${ }^{1}$, Gutemberg Borges França ${ }^{2}$, Francisco Leite de Albuquerque Neto ${ }^{2, *}$ \\ and Ismail Gultepe ${ }^{3,4,5}$
}

1 Integrated Center of Aeronautical Meteorology, Rio de Janeiro 21941-520, Brazil; fabricio@lma.ufrj.br

2 Applied Meteorology Laboratory, Federal University of Rio de Janeiro, Rio de Janeiro 21941-916, Brazil; gutemberg@lma.ufrj.br

3 Meteorological Research Division, Environment and Climate Change Canada, OBRS,

Toronto, ON M3H 5T4, Canada; ismail.gultepe@canada.ca

4 Engineering and Applied Science, Ontario Tech University, Oshawa, ON L1G 0C5, Canada

5 Faculty of Engineering, Istinye University, Istanbul 34396, Turkey

* Correspondence: albuquerque@lma.ufrj.br

check for updates

Citation: Cordeiro, F.M.; França, G.B. de Albuquerque Neto, F.L.; Gultepe, I. Visibility and Ceiling Nowcasting Using Artificial Intelligence Techniques for Aviation Applications. Atmosphere 2021, 12, 1657. https:// doi.org/10.3390/atmos12121657

Academic Editor: Da-Lin Zhang

Received: 1 November 2021

Accepted: 25 November 2021

Published: 10 December 2021

Publisher's Note: MDPI stays neutral with regard to jurisdictional claims in published maps and institutional affiliations.

Copyright: (c) 2021 by the authors. Licensee MDPI, Basel, Switzerland. This article is an open access article distributed under the terms and conditions of the Creative Commons Attribution (CC BY) license (https:/ / creativecommons.org/licenses/by/ $4.0 /)$.

\begin{abstract}
This work presents a novel approach for simulating visibility (Vis) and ceiling base height $\left(\mathrm{H}_{\mathrm{C}}\right)$ in up to $1 \mathrm{~h}$ using several machine learning $(\mathrm{ML})$ algorithms. Ten years of meteorological data at 15 min intervals for Santos Dumont airport (SDA), Rio de Janeiro, Brazil were used in the ML method training and testing process. In the investigation, several categorical and regressive algorithms were trained and tested, and the results were verified with observations. The forecast results reveal that the categorical methods produced satisfactory results only up to $15 \mathrm{~min}$ for visibility prediction with the probability of detection greater than $85 \%$. On the other hand, the regressive methods were found to be more capable of generating an accurate prediction of Vis and $\mathrm{H}_{\mathrm{c}}$ compared to categorical method up to $60 \mathrm{~min}$. The forecast evaluation metrics for Vis and $\mathrm{H}_{\mathrm{c}}$ had correlation coefficients of $0.99 \pm 0.00$ and $0.96 \pm 0.00$, with mean absolute errors of $324 \pm 77 \mathrm{~m}$, and $167 \pm 21 \mathrm{~m}$, respectively. Results suggested that ML methods can improve the prediction of Vis and $\mathrm{H}_{\mathrm{c}}$ up to $1 \mathrm{~h}$ when accurate observations are used for the analysis.
\end{abstract}

Keywords: aviation meteorology; aeronautical meteorology; weather prediction; nowcasting; visibility; ceiling

\section{Introduction}

Visibility and low ceiling parameters are often a matter of concern in aircraft landing operations because of their obstruction of the pilot's view over the airport. The Instrument Landing System (ILS), an accurate vertical and lateral landing guiding technology, permits airplanes to land with significantly reduced visibility and ceiling. Despite the fact that many airports have been certified to operate in accordance with instrument flight rules (IFR), some of them lack ILS and must rely on often inaccurate weather forecasts to avoid an unexpected landing impossibility due to visibility or ceiling limitations. According to the Brazilian Aeronautical Information Service (www.aisweb.decea.mil.br, accessed on 15 July 2021), there are 141 airports in Brazil that are approved for IFR operations, although only 47 of them presently have an ILS. Although rain and drizzle may impact the visibility and ceiling height $\left(\mathrm{H}_{\mathrm{c}}\right)$ significantly, mist and fog are the most restrictive events affecting the mentioned parameters in Brazilian airports [1].

Recently, a review of aviation meteorological issues presented all types of weather events that are critical for aviation operations [2]. It stated that aviation accidents related to Vis and $\mathrm{H}_{\mathrm{c}}$ can reach up to about $30 \%$, and come after wind impact.

The genesis of fog/mist in forecast models is usually a significant problem due to poor representation of the microphysical and aerosol properties [2]. For example, an objective 
$12 \mathrm{~h}$ fog prediction model was developed based on the curve adjustment analysis via the least-squares technique of the observational data for Porto Alegre airport [3]; a numerical weather forecasting model for the regional scales was utilized to investigate the evolution of local mesoscale circulation and its impact on the occurrence of night fog formation in São Paulo [4]; and an alternative stochastic model for fog forecasting was established for the Guarulhos International Airport [5]. A visibility forecasting model developed in the early 1980s for fog events at the airports of Curitiba and Porto Alegre concludes that detailed observations and improved physical algorithms are required for accurate Vis predictions [6] Moreover, investigations $[7,8]$ on the physical and synoptic processes of coastal fog/stratus clouds concluded that they are related to a wave disturbance field in trade winds in northern Brazil and a high-pressure displacement along South America's east coast in conjunction with a low hot core barotropic occurrence in northern Argentina $[9,10]$ These studies highlighted the difficulty in forecasting the life cycle of marine and coastal fog.

Later in the 2000s, machine learning was limited to a single ML algorithm for visibility and ceiling predictions [11]. A neural network was tested to diagnose Vis using the Met Office's unified model prediction [12]. This study concludes that the performance of the parameterization is determined by the quality of the meteorological input parameters and the structure of the parameterization. Because of the changing weather conditions over short time periods, weather parameters are critical to improving aviation operations. Then, a pioneering method for very short-term forecasting [13] was developed based on neural network algorithms to predict the Vis and $\mathrm{H}_{\mathrm{c}}$ at Guarulhos Airport, São Paulo. Similarly, a fog prediction method based on a ML algorithm was developed for the Brazilian Air Force aerodrome at Pirassununga using meteorological observation data collected from 1989 to 2008 , and it was concluded that the suggested neural network algorithm predictions are 95 percent equivalent to observations [14]. A series of works [15-17], explored the use of ML algorithms for short-term forecasting of convective events for the Rio de Janeiro metropolitan region. The current results of the ML algorithms show that they are capable of nowcasting convective events with a high probability and low false alarm ratio. Recently, a fog forecasting method based on the ML algorithm was developed for the Afonso Pena International Airport in Paraná, Brazil [18]. The algorithm diagnoses Vis based on $15 \mathrm{~min}$ observed and predicted meteorological data, from the automatic surface meteorological station and simulated data using the numerical model of Weather Research and Forecast, respectively. The correlation coefficient of the $24 \mathrm{~h}$ forecast, at $15 \mathrm{~min}$ intervals, and the observations is close to $90 \%$. The fog predictions are slightly biased, i.e., with a delayed onset and anticipated demise in $30 \mathrm{~min}$ or less.

On the other hand, numerical weather prediction (NWP) models perform poorly for low visibility and ceiling predictions [19]. In 2015, an investigation was conducted on the impact of the horizontal resolution of a regional climate model (RCM) on the reproduction of local weather characteristics related to fog in the metropolitan region of São Paulo [20]. RCM simulations showed the ability to characterize fog events with horizontal resolutions of $50 \mathrm{~km}$ and $20 \mathrm{~km}$ using data from June to September for 2003 and 2004 and stated that increased resolution resulted in prediction improvement of the fog occurrence.

The landing procedure in adverse weather conditions at the SDA in Rio de Janeiro is usually difficult for three reasons: (1) its runways are short; (2) there is no ILS to be used; and (3) its location is very close to the Rio Janeiro-Niterói bridge and Sugarloaf Mountain, as seen in Figure 1a,b. According to the INFRAERO (Airport Management Company, Brasília, Brazil) yearbook [21], approximately 100,144 aircraft landed during 2018, 9,206,059 passengers traveled through the SDA, and it was ranked as the third airport in Brazil that was most impacted by visibility restrictions. The Rio-São Paulo air bridge runs between Santos Dumont and Congonhas Airports, connecting the two largest cities in Brazil and representing $58 \%$ of SDA movements, with an average duration of $45 \mathrm{~min}$. 


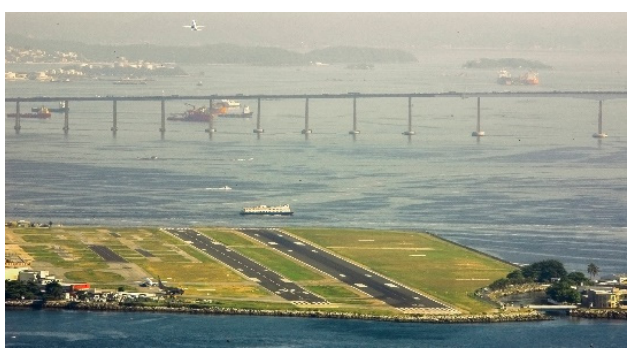

(a)

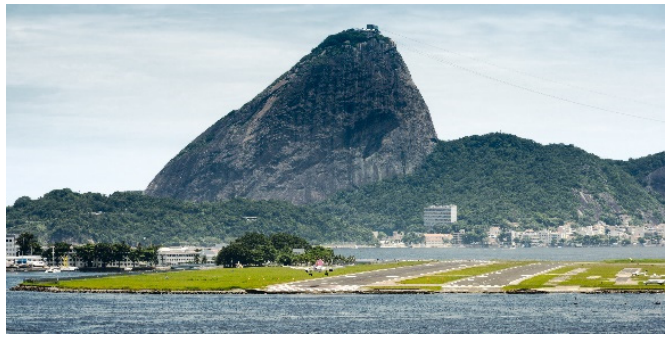

(b)

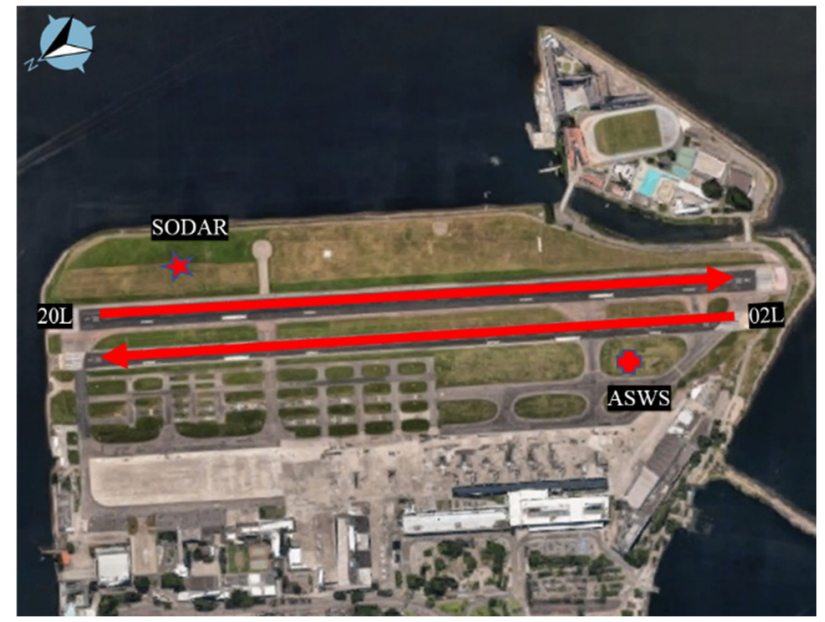

(c)

Figure 1. Views from the north (a) and south (b) directions for the SDA runways 02 and 20 (red arrows), SODAR (star) and the automatic surface weather station-ASWS (cross) are shown in (c). Source: Images used with permission from Shutterstock and the map is adapted from www.google.com.br/maps, accessed on 24 November 2021.

The focus of this research is to use machine-learning-based regressive and categorical algorithms to develop new short-term Vis and $\mathrm{H}_{\mathrm{c}}$ forecasts for SDA, with potential general application to other Brazilian airports. In this work, Section 2 provides the location of the project and observations. Section 3 presents the methods and characteristics of the ML algorithms used in the work. Section 4 is for the results. Section 5 is the conclusions derived from this work.

\section{Project Site and Observations}

The SDA is located at $22.9103^{\circ} \mathrm{S}$ and $43.1631^{\circ} \mathrm{W}$, near the center of Rio de Janeiro. Figure 1 shows the airport views from the northern and southern points. The Sugarloaf Mountain (pique at $407 \mathrm{~m}$ ) $4000 \mathrm{~m}$ away from the two airport runways is shown in Figure 1c. The length of main runway identified as $20 \mathrm{~L} / 02 \mathrm{R}$ is $1323 \mathrm{~m}$ long, and only $63 \mathrm{~m}$ longer than the secondary runway $(20 \mathrm{R} / 02 \mathrm{~L})$.

Considering the aircraft landing restrictions imposed by the obstacles, the Airspace Control Department established the visibility and ceiling limits for landing on the runways. Table 1 presents the operational limits for visibility $(\mathrm{m})$ and ceiling height (feet) for the three main landing procedures at SDA. These procedures are (1) Area Navigation/Global Navigation Satellite Systems (RNAV/GNSS), (2) Non-Directional Beacon (NDB), and (3) Area Navigation/Required Navigation Performance (RNAV/RNP). 
Table 1. Shows the operational limits for Vis and ceiling representing the three landing procedures on the runways of the SDA.

\begin{tabular}{ccc}
\hline \multirow{2}{*}{ Landing Procedure } & \multicolumn{2}{c}{ Runway } \\
\cline { 2 - 3 } & $\mathbf{2 0}$ & $\mathbf{2}$ \\
\hline (1) RNAV/GNSS & $4500 \mathrm{~m} / 1000$ feet & $5000 \mathrm{~m} / 1000$ feet \\
(2) NDB & $3700 \mathrm{~m} / 1200$ feet & $4800 \mathrm{~m} / 1500$ feet \\
(3) RNAV/RNP & $1600 \mathrm{~m} / 300$ feet & $1600 \mathrm{~m} / 300$ feet \\
\hline
\end{tabular}

Observations for this work came from three sources: (1) SOnic Detection And Ranging (SODAR) as atmospheric profiler; (2) Automatic Surface Weather Station (ASWS); and (3) human observers. Table 2 shows details about the data sources and the 253 meteorological variables labeled as primary (collected directly from the meteorological instruments) and derived (determined using the primary). The parameters used are the predominant visibility (Vis), the ceiling $\left(\mathrm{H}_{\mathrm{c}}\right)$, cloud cover $\left(\mathrm{C}_{\mathrm{c}}\right)$, or cloud quantity $\left(\mathrm{C}_{\mathrm{q}}\right)$, low cloud cover in okta $\left(C_{\text {lcc }}\right)$, backscatter intensity $(\beta)$, surface horizontal wind direction in degrees $\left(\theta_{\text {dir }}\right)$ and horizontal wind speed $\left(\mathrm{U}_{\mathrm{h}}\right)$, zonal wind component $(\mathrm{u})$, meridional wind component $(\mathrm{v})$, vertical air velocity $\left(\mathrm{w}_{\mathrm{a}}\right)$, turbulent kinetic energy in (TKE), energy dissipation rate (EDR), relative humidity to water in $\%\left(\mathrm{RH}_{\mathrm{w}}\right)$, surface atmospheric pressure $\left(\mathrm{P}_{\mathrm{S}}\right)$, dew point temperature $\left(T_{d}\right)$, and air temperature $\left(T_{a}\right)$. The red star and cross in Figure $1 c$ represent the locations of SODAR and ASWS at SDA, respectively.

Table 2. Observation characteristics and meteorological variables used in the machine learning algorithms during training and testing. A total of 253 meteorological variables were used in the analysis.

\begin{tabular}{|c|c|c|c|c|c|c|c|}
\hline \multirow{2}{*}{\multicolumn{2}{|c|}{$\begin{array}{c}\text { Source } \\
\text { Freq. } \\
\text { (min) }\end{array}$}} & \multirow{2}{*}{\multicolumn{2}{|c|}{$\begin{array}{l}\text { (Input) Variable } \\
\text { Primary Derived }\end{array}$}} & \multirow{2}{*}{ Variabl qty. } & \multirow{2}{*}{ Record qty. } & \multirow{2}{*}{ Data Period } & \multirow{2}{*}{ Output } \\
\hline & & & & & & & \\
\hline$(1)$ & 15 & $\begin{array}{c}\beta(\mathrm{h},-\mathrm{t}), \text { where } \\
\mathrm{h} \text { and } \mathrm{t} \text { are equal to } 30, \\
40,50,60 \text { e } 70 \mathrm{~m} \text { and } 0, \\
15,30,45,60 \text { and } \\
120 \text { min, respectively }\end{array}$ & $\begin{array}{c}\mathrm{u}(\mathrm{h},-\mathrm{t}), \mathrm{v}(\mathrm{h},-\mathrm{t}), \\
\mathrm{w}_{\mathrm{a}}(\mathrm{h},-\mathrm{t}), \\
\text { EDR }(\mathrm{h},-\mathrm{t}) \text { and } \\
\text { TKE }(\mathrm{h}, \mathrm{t}), \text { where } \\
\mathrm{h} \text { and } \mathrm{t} \text { are equal } \\
\text { to } 30,40,50,60 \mathrm{e} \\
70 \mathrm{~m} \text { and } 0,15, \\
30,45,60 \text { and } \\
120 \text { min, } \\
\text { respectively }\end{array}$ & 150 & 70,080 & 2017 to 2018 & \multirow{3}{*}{$\begin{array}{l}\text { Visibility-range-t } \\
\text { (where range is } \\
\text { equal to } 4500,3700, \\
1600 \mathrm{~m} \text { ) and/or } \\
\text { Ceiling-range-t } \\
\text { (being equal to } \\
1000 \mathrm{ft} \text { )/ cloud quant } \\
\text { (okta) for forecast } \\
\text { periods (where } \mathrm{t} \text { is } \\
\text { equal to } 15,30, \\
45 \text { and } 60 \mathrm{~min} \text { ). }\end{array}$} \\
\hline$(2)$ & $15^{*}$ & $\begin{array}{c}\text { Month, Julian day, } \\
\text { year, hour, Ta }(h, t), \\
\theta_{\text {dir }}(h,-t), \\
\mathrm{U}_{\mathrm{h}}(\mathrm{h},-\mathrm{t}), \mathrm{RH}_{\mathrm{w}}(\mathrm{h},-\mathrm{t}), \\
\mathrm{T}_{\mathrm{d}}(\mathrm{h},-\mathrm{t}), \mathrm{P}_{\mathrm{s}}(\mathrm{h}, \mathrm{t}) \text { and } \\
\mathrm{RH}_{\mathrm{w}}(\mathrm{h}, \mathrm{t}), \mathrm{H}_{\mathrm{c}}(\mathrm{t})^{*} \\
\text { where } \mathrm{h} \text { and } \mathrm{t} \\
\text { is equal } 2 \text { and } \\
0,15,30,45,60 \text { and } \\
120 \text { min), respectively }\end{array}$ & $\longrightarrow$ & 73 & 350,400 & 2009 to 2018 & \\
\hline (3) & $60 * *$ & - & $\begin{array}{c}\text { Vis }(-t), \\
\text { Ceiling }(-t), \\
C_{q}(-t), \\
C_{c}(-t), C_{l c c}(-t), \\
\text { where } t \text { is equal to } \\
0,15,30,45, \\
60 \text { and } 120 \mathrm{~min}\end{array}$ & 30 & 87,600 & 2009 to 2018 & \\
\hline
\end{tabular}

\footnotetext{
${ }^{*}$ The ceiling height is registered automatically by a ceilometer which is part of the ASWS instrument set. ${ }^{* *}$ For when restriction
} has occurred. 


\section{Method}

In this work, machine learning analysis with categorical or regressive algorithms were used to evaluate Vis and $\mathrm{H}_{\mathrm{c}}$ predictions at the SDA, because they are commonly used to recognize physical patterns in a specific data set. They are based on the principle that it is possible to learn from a set of training data and consequently be able to correctly classify new standards [22]. This research is part of a sequence of short-term prediction studies based on machine learning algorithms that have been carried out by the Applied Meteorology Laboratory at the Federal University of Rio de Janeiro and can be found in the work of $[13,15-18,23,24]$. So, in the present study, the WEKA (Waikato Environment for Knowledge Analysis) software package (version 3.8.4) [25] developed by the University of Waikato in New Zealand was used, with and without the Auto-WEKA subsystem [26,27]. WEKA was chosen because it has a series of machine-learning-based algorithms that can be used to classify thermodynamic atmospheric patterns in the data set related with Vis and $\mathrm{H}_{\mathrm{c}}$ limits at the SDA.

\subsection{Detailed Analysis}

Knowing that meteorological observations represent the variation in time and space of the local atmospheric thermodynamic behavior, local atmospheric patterns with restricted Vis and $\mathrm{H}_{\mathrm{c}}$ thresholds for landing procedures were obtained at the above-mentioned airport, following the steps below:

i. Taking the 15 min ASWS data as a reference, the other data were chronologically disposed, and then their statistical consistency was verified. Data were represented at 15, 30, $45 \mathrm{~min}$ for each hour, and all the observations were interpolated to the same time intervals (Table 2). Overall, the number of observations at $15 \mathrm{~min}$ intervals reached 350,400 data;

ii. The history of event occurrences that were limited by the airport operating Vis and $\mathrm{H}_{\mathrm{c}}$ threshold values were examined;

iii. The inputs (the meteorological variables, primary and derived) were selected by measuring the cross-correlation between a given variable and the class (output), and then the redundant ones were eliminated;

iv. Data sets were generated in order to train and test categorical and regression algorithms. For categorical data sets, the vector input was represented by variables (in columns 2 and 3 of Table 2), that met the intervals of Vis(t) $\leq 4500,3700,1600 \mathrm{~m}$, connected to respective outputs associated with the advanced values of Vis $(+t)$ for each prediction time of 15, 30, 45, and $60 \mathrm{~min}$. These inputs were then connected to a binary output (target) of YES or NO, depending on whether the Vis intervals was satisfied. For regressive data sets, the vector inputs (variables) were directly coupled to the Vis $(+\mathrm{t})$ or $\mathrm{H}_{\mathrm{c}}(+\mathrm{t}) / \mathrm{C}_{\mathrm{q}}(+\mathrm{t})$ values of each prediction time of $15,30,45$, and $60 \mathrm{~min}$ (because of the uncertainty in the observation of ceiling data, only regressive algorithms were used for ceiling prediction);

v. The data sets (categorical and regressive) were then randomly divided into $60 \%$ for training and $40 \%$ for testing the categorical and regressive algorithms, respectively. This is a frequent practice to avoid overfitting, which occurs when a statistical model fits previously observed data very well but fails to predict new results.

vi. The YES and NO records of the categorical algorithms training dataset, defined in step v, were balanced through the WEKA ClassBalancer option in four configurations: (1) unmodified data set, (2) 50\% YES, and 50\% NO, (3) $60 \%$ YES and $40 \%$ NO, (4) $65 \%$ YES and $35 \%$ NO for the prediction times using operational thresholds. For regressive algorithms, the training test data sets were defined as in step iv without any artificial adjustment;

vii. Cross-validation approach (this includes dividing the complete data set into $\mathrm{k} \mathrm{mu}$ tually exclusive subsets of the same size, one for testing and the remaining k-1 for parameter estimation and assessing the algorithm's accuracy, [28]) was used to train all categorical algorithms available in WEKA, with the four training dataset con- 
figurations defined in step vi. Similarly, regressive algorithms were trained. The forecast preliminary findings were examined, and the algorithms with the highest performance (here referred to as selected ones) were chosen for future examination.

viii. Using the proper test dataset to run the algorithm tests. Sections $4.3-4.6$ discuss the results of the highest performing category and regressive selected algorithms with WEKA's default configuration.

ix. Training-test experiments for each prediction time were carried out using the categorical or regressive original data set with Auto-WEKA (version 2.0) [27]. In this tool, all available algorithms were tested and their hyperparameters optimized, which employs the unmodified dataset partitioned into 70\% training and 30\% testing (thus step iv is ignored here) [26]. Each experiment yielded a rank of the top-performing algorithms from best to worst.

\subsection{Algorithm Evaluation}

The WEKA software with several classical statistics was used to evaluate the performance of categorical and regressive algorithms. The categorical algorithms have their forecasts versus the observed values by using a two-dimensional contingency table that makes it possible to determine the following categorical statistics [29]: (1) probability of detection (POD) that is a measured fraction of observed events that were correctly predicted-a perfect score is 1 ; (2) false alarm ratio (FAR), a measure of the fraction of YES predictions in which the event did not occur-a perfect score is 0; (3) BIAS, which measures the proportion of the event frequency prediction by the frequency of the observed events - a perfect score is 1 ; (4) F-measure (F-M), a measure of the accuracy of a test-a perfect score is 1; and (5) KAPPA, a way of measuring the performance of the binary classification algorithms, where the perfect agreement is 1 [30].

The WEKA software evaluates regressive algorithms that have their performances mainly evaluated by the four following statistics [29]: (1) correlation coefficient (CC), which represents a measure of linear correlation between the forecasts and observations. It varies from +1 and 1 , where here values near 1 are desired. (2) Mean absolute error (MAE), which is a measure of error between paired observation and forecasts. The perfect score is zero. (3) Relative absolute error (RAE), expressed as a ratio, comparing the mean residual error to errors produced by a trivial method. The result of a practical method (or its predictions are better than a trivial method) generates a ratio of less than one.

\subsection{Characteristics of the Selected ML Algorithms}

The statistical evaluation of All WEKA's algorithms with default configuration given in step vii indicated that the following five algorithms performed better than the others, given as follows:

(1) Bayes Net (BN) is a classifier based on the construction of a Bayesian network, using various research algorithms and quality measures, which provides data structures, network structures, and conditional probability distributions, and can classify binary, class values absent, and nominal classes. [25]. (2) Multilayer Perceptron (MP) consists of standard perceptron with a defined number of hidden units using the activation function (for example, ReLu or sigmoid) and optimization based on minimizing the loss of quadratic error function [25]. (3) Random Forest (RF) is a classifier that consists of a collection of tree classifiers and is trained in different subsets of input resources, and the one with the best performance is chosen [31]. (4) REPTree (RT) is a quick decision tree, which uses the logic of the decision and regression tree and creates several trees in different iterations, selecting the best of all trees generated through the mean square error [25]. Finally, (5) the Hoeffding Tree (HT) consists of a decision tree induction algorithm capable of learning from large data streams, assuming that the distribution generation examples does not change over time, as well as exploring the fact that a small sample may be sufficient to choose an ideal division attribute [25]. 


\section{Results}

In this section, results are presented for Vis and $\mathrm{H}_{\mathrm{c}}$ predictions using the strategy described in the method section.

\subsection{Visibility Thresholds}

The data set had occurrences of 11,070, 3996, and 728 low visibility events at $15 \mathrm{~min}$ intervals with Vis $\leq 4500,3700$, and $1600 \mathrm{~m}$, respectively. Figure 2 illustrates the hourly (a) and monthly (b) distributions of these events. This reveals that the three main aircraft landing procedures, (1) RNAV/GNSS, (2) NDB and (3) RNAV/RNP (Table 1), were in some ways are compromised by visibility restriction every hour of the day, with a critical period just before sunrise until close to noon (approximately from $06 \mathrm{am}$ to $11 \mathrm{am}$ ) throughout all months, and a critical period between May and July.

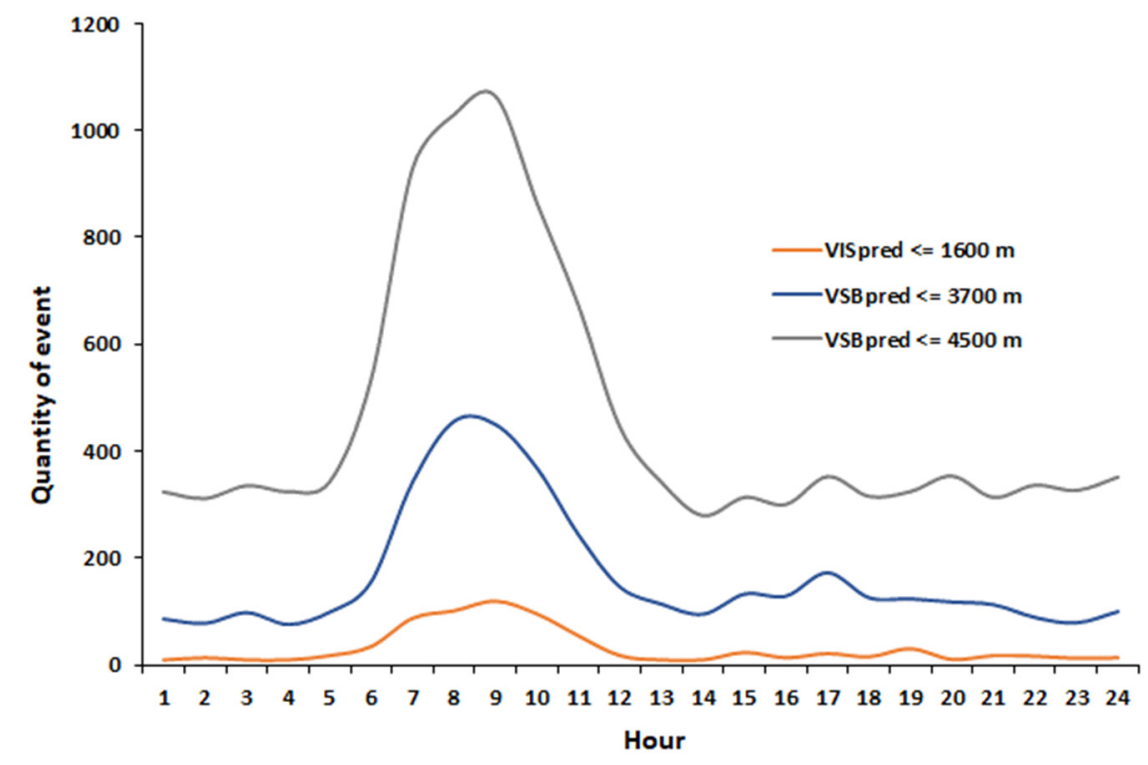

(a)

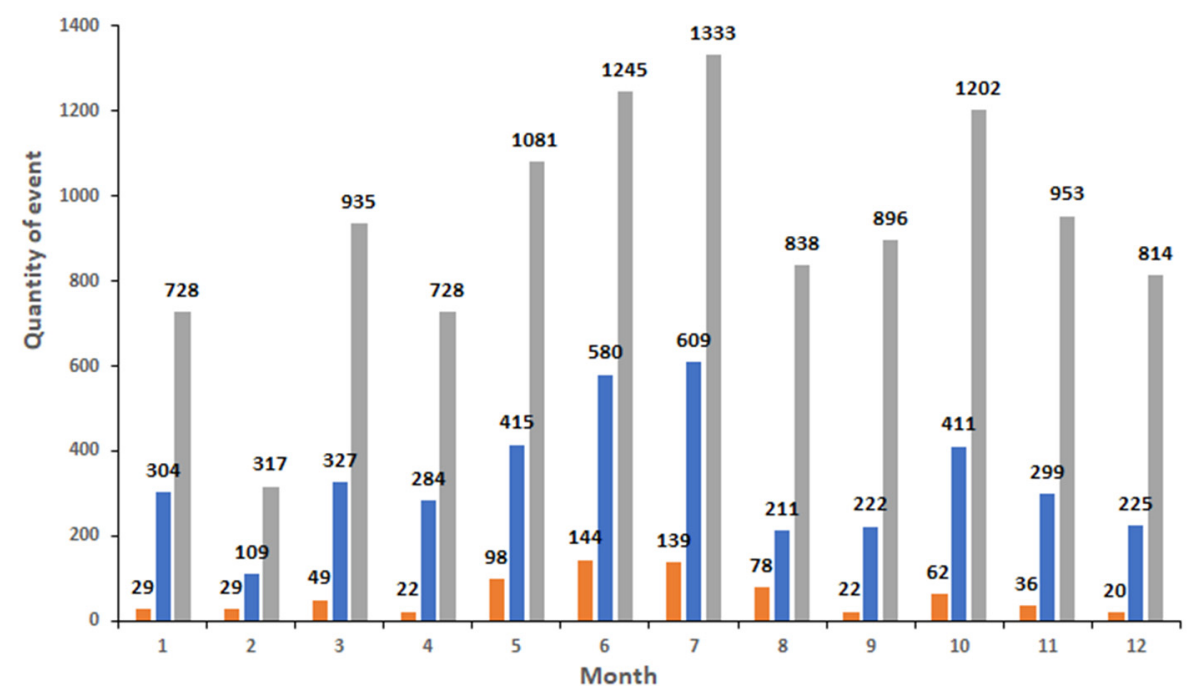

(b)

Figure 2. Representation of the hourly (a) and monthly (b) distribution of 15 min meteorological records where visibility was below or equal to the limits of 4500 (bars and lines in gray), 3700 (bars and lines in blue), and 1600 (bars and lines in orange) meters, respectively. 


\subsection{Ceiling Thresholds}

Similar to Vis analysis, using a ceiling-related threshold, Figure 3 illustrates the hourly (a) and monthly (b) distributions of 4736 events with $\mathrm{H}_{\mathrm{c}} \leq 1000 \mathrm{ft}$ from May to July, which is the most critical period. Figure $3 \mathrm{~b}$ reveals that the RNAV/GNSS (1) landing procedure is affected in some way for the entire day. The critical period usually occurred before sunrise until close to noon (06 a.m.-11 a.m.).

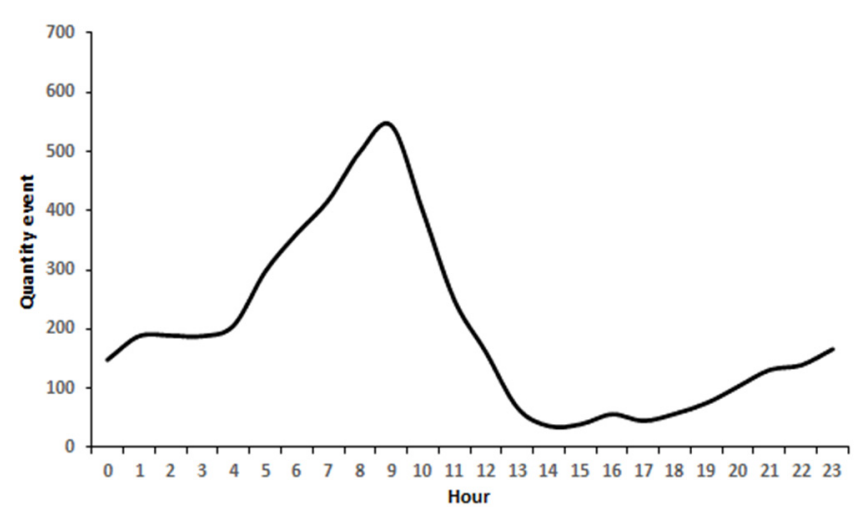

(a)

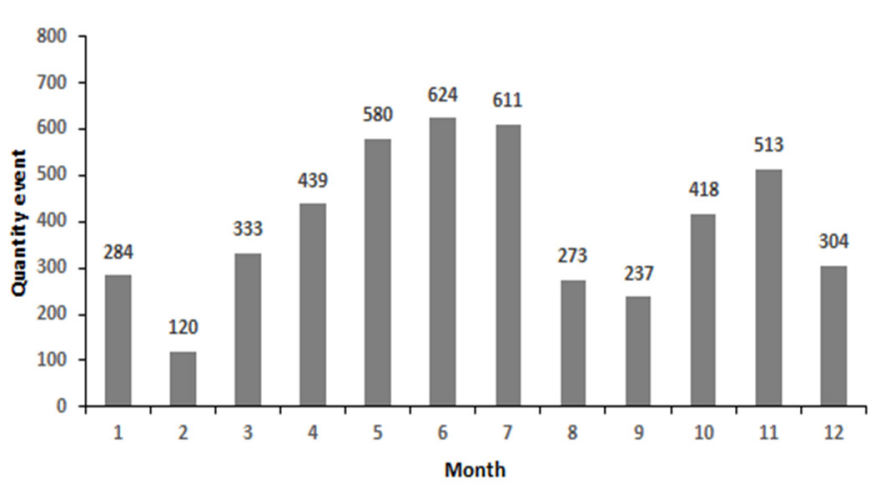

(b)

Figure 3. Representation of the hourly (a) and monthly (b) distribution of 473615 min meteorological records where the ceiling was $\leq 1000 \mathrm{ft}$.

\subsection{Algorithm Training and Results}

The task of training and testing machine learning algorithms is time-consuming, and success depends directly on the choice of variables (input) that characterize weather hazard conditions, such as the local thermodynamic state of the atmosphere that precedes the occurrence of restrictions on the operational thresholds of Vis and $\mathrm{H}_{\mathrm{c}}$. Table 2 lists the 253 primary and derived meteorological variables as predictors. Thus, disregarding the 150 variables generated by SODAR (data source 1) in method step vi, the cross-correlation of the remaining 103 variables were analyzed and the redundant ones were eliminated, resulting in an input data set consisting of 20 components, namely: month, Julian day, hour, $\theta_{\text {dir }}(2,0), \mathrm{U}_{\mathrm{h}}(2,0), \mathrm{U}_{\mathrm{h}}(2,-15), \mathrm{U}_{\mathrm{h}}(2,-30), \mathrm{cl}(0), \mathrm{C}_{\mathrm{lcc}}(0), \mathrm{T}_{\mathrm{a}}(2,0), \mathrm{T}_{\mathrm{d}}(2,0), \mathrm{RH}_{\mathrm{w}}(2,0), \mathrm{P}_{\mathrm{s}}(2,0)$, Vis $(0)$, Vis $(-15)$, Vis $(-30)$, Vis $(-45)$, Vis $(-60)$, and Vis $(-120)$. These were the inputs used in the various training procedures for the Vis and $\mathrm{H}_{\mathrm{c}}$ prediction algorithms. For experiments of training algorithms that included data from SODAR, the cross-correlation of the variables was also analyzed.

Several experiments of training and testing via cross-validation for 15-min forecasting of Vis $\leq 4500 \mathrm{~m}$ and $\mathrm{H}_{\mathrm{c}} \leq 1000$ feet were carried out using all available WEKA's algorithms with the goal of selecting ML WEKA's algorithms for future investigation (step vii). Following an evaluation of the performance results of the algorithms, the five algorithms in Section 3.2 were selected and discussed further.

\subsection{Visibility Categorical Nowcasting}

Experiments were carried out in order to assess visibility forecasts, and the following requirements were satisfied, namely: (1) the five categorical WEKA algorithms selected (step viii in the method section); (2) the three visibility thresholds used were Vis $\leq 4500$, $\leq 3700$, and $\leq 1600$; (3) the four prediction times had $15 \mathrm{~min}$ intervals up to $60 \mathrm{~min}$; and (4) data set configuration was based on SODAR data or not, also using Auto-WEKA support (namely Auto-WEKA default).

Tables 3-8 show the best test results of the 15 and 30 min predictions for the three defined visibility thresholds for the five selected algorithms (here called optimal). It is observed that the performance of the forecast decreases as the prediction time increases and the visibility limit decreases. So that all statistics had the unit's ideal value, 1-FAR 
was adopted. Here, it was defined as whether a given method (the latter being defined as the trained and tested algorithms) had satisfactory performance to predict visibility for a given prediction time when their POD and 1-FAR values were $\geq 0.8$. Tables $3-5$ highlights the statistical results of the $15 \mathrm{~min}$ forecast (and those satisfactory algorithms in bold) for visibility thresholds, and reveals that eleven algorithms performed coherently, since the averages of the categorical statistics were almost close to the perfect score (value in parentheses), which were: POD $(\mathrm{Y}, \mathrm{N})(0.884 \pm 0.012,0.999 \pm 0.000), 1$-FAR $(\mathrm{Y}, \mathrm{N})$ $(0.996 \pm 0.005,0.884 \pm 0.012), \mathrm{F}-\mathrm{M}(\mathrm{Y}, \mathrm{N})(0.891 \pm 0.011,0.998 \pm 0.001), \mathrm{BIAS}(\mathrm{Y}, \mathrm{N})$ $(1.016 \pm 0.022,1.000 \pm 0.000), \mathrm{KAPPA}(0.89 \pm 0.008)$.

Table 3. Statistical test results of $15 \mathrm{~min}$ Vis forecasts $\leq 4500 \mathrm{~m}$ for the five algorithms (Alg) selected with input from SODAR (source 1), ASWS (source 2) and observer (source 3). The satisfactory algorithm result is in bold.

\begin{tabular}{cccccccccccc}
\hline Alg & $\begin{array}{c}\text { Input } \\
\text { Data }\end{array}$ & $\begin{array}{c}\text { POD } \\
\text { (YES) }\end{array}$ & $\begin{array}{c}\text { 1-FAR } \\
\text { (YES) }\end{array}$ & $\begin{array}{c}\text { F-M } \\
\text { (YES) }\end{array}$ & $\begin{array}{c}\text { BIAS } \\
\text { (YES) }\end{array}$ & $\begin{array}{c}\text { POD } \\
\text { (NO) }\end{array}$ & $\begin{array}{c}\text { 1-FAR } \\
\text { (NO) }\end{array}$ & $\begin{array}{c}\text { F-M } \\
\text { (NO) }\end{array}$ & $\begin{array}{c}\text { BIAS } \\
\text { (NO) }\end{array}$ & $\begin{array}{c}\text { KAPPA } \\
\text { Configuration }\end{array}$ \\
\hline BN & 2 and 3 & 0.83 & 0.99 & 0.72 & 0.77 & 0.99 & 0.83 & 0.99 & 0.99 & 0.71 & 4 \\
MP & 2 and 3 & $\mathbf{0 . 8 8}$ & $\mathbf{1 . 0 0}$ & $\mathbf{0 . 9 1}$ & $\mathbf{1 . 0 4}$ & $\mathbf{1 . 0 0}$ & $\mathbf{0 . 8 8}$ & $\mathbf{1 . 0 0}$ & $\mathbf{1 . 0 0}$ & $\mathbf{0 . 9 0}$ & $\mathbf{1}$ \\
RF & 2 and 3 & $\mathbf{0 . 9 1}$ & $\mathbf{1 . 0 0}$ & $\mathbf{0 . 9 1}$ & $\mathbf{0 . 9 9}$ & $\mathbf{1 . 0 0}$ & $\mathbf{0 . 9 1}$ & $\mathbf{1 . 0 0}$ & $\mathbf{1 . 0 0}$ & $\mathbf{0 . 9 1}$ & Auto-WEKA \\
HT & $\mathbf{2}$ and 3 & $\mathbf{0 . 9 1}$ & $\mathbf{1 . 0 0}$ & $\mathbf{0 . 9 1}$ & $\mathbf{1 . 0 0}$ & $\mathbf{1 . 0 0}$ & $\mathbf{0 . 9 1}$ & $\mathbf{1 . 0 0}$ & $\mathbf{1 . 0 0}$ & $\mathbf{0 . 9 1}$ & $\mathbf{1}$ \\
RT & 2 and 3 & $\mathbf{0 . 8 9}$ & $\mathbf{1 . 0 0}$ & $\mathbf{0 . 9 0}$ & $\mathbf{1 . 0 3}$ & $\mathbf{1 . 0 0}$ & $\mathbf{0 . 8 9}$ & $\mathbf{1 . 0 0}$ & $\mathbf{1 . 0 0}$ & $\mathbf{0 . 9 0}$ & $\mathbf{1}$ \\
RF & $\mathbf{1}$ 2 and 3 & $\mathbf{0 . 8 9}$ & $\mathbf{1 . 0 0}$ & $\mathbf{0 . 8 9}$ & $\mathbf{1 . 0 0}$ & $\mathbf{1 . 0 0}$ & $\mathbf{0 . 8 9}$ & $\mathbf{1 . 0 0}$ & $\mathbf{1 . 0 0}$ & $\mathbf{0 . 8 9}$ & Auto-WEKA \\
\hline
\end{tabular}

Table 4. Statistical test results of $15 \mathrm{~min}$ Vis forecasts $\leq 3700 \mathrm{~m}$ for the five algorithms (Alg) selected with input from SODAR (source 1), ASWS (source 2) and observer (source 3). The satisfactory algorithm result is in bold.

\begin{tabular}{cccccccccccc}
\hline Alg & $\begin{array}{c}\text { Input } \\
\text { Data }\end{array}$ & $\begin{array}{c}\text { POD } \\
\text { (YES) }\end{array}$ & $\begin{array}{c}\text { 1-FAR } \\
\text { (YES) }\end{array}$ & $\begin{array}{c}\text { F-M } \\
\text { (YES) }\end{array}$ & $\begin{array}{c}\text { BIAS } \\
\text { (YES) }\end{array}$ & $\begin{array}{c}\text { POD } \\
\text { (NO) }\end{array}$ & $\begin{array}{c}\text { 1-FAR } \\
\text { (NO) }\end{array}$ & $\begin{array}{c}\text { F-M } \\
\text { (NO) }\end{array}$ & $\begin{array}{c}\text { BIAS } \\
\text { (NO) }\end{array}$ & $\begin{array}{c}\text { KAPPA } \\
\text { Configuration }\end{array}$ \\
\hline BN & 2 and 3 & 0.89 & 0.97 & 0.37 & 0.26 & 0.97 & 0.89 & 0.98 & 0.97 & 0.36 & 1 \\
MP & 2 and 3 & 0.84 & 1.00 & 0.88 & 1.10 & 1.00 & 0.84 & 1.00 & 1.00 & 0.88 & 1 \\
RF & 2 and 3 & $\mathbf{0 . 8 8}$ & $\mathbf{1 . 0 0}$ & $\mathbf{0 . 8 9}$ & $\mathbf{1 . 0 1}$ & $\mathbf{1 . 0 0}$ & $\mathbf{0 . 8 8}$ & $\mathbf{1 . 0 0}$ & $\mathbf{1 . 0 0}$ & $\mathbf{0 . 8 8}$ & $\mathbf{3}$ \\
HT & 2 and 3 & 0.82 & 1.00 & 0.86 & 1.12 & 1.00 & 0.82 & 1.00 & 1.00 & 0.86 & 1 \\
RT & $\mathbf{2}$ and 3 & $\mathbf{0 . 8 5}$ & $\mathbf{1 . 0 0}$ & $\mathbf{0 . 8 9}$ & $\mathbf{1 . 0 9}$ & $\mathbf{1 . 0 0}$ & $\mathbf{0 . 8 5}$ & $\mathbf{1 . 0 0}$ & $\mathbf{1 . 0 0}$ & $\mathbf{0 . 8 8}$ & $\mathbf{1}$ \\
RF & $\mathbf{1 , 2}$ and 3 & $\mathbf{0 . 8 5}$ & $\mathbf{1 . 0 0}$ & $\mathbf{0 . 8 5}$ & $\mathbf{1 . 0 0}$ & $\mathbf{1 . 0 0}$ & $\mathbf{0 . 8 5}$ & $\mathbf{1 . 0 0}$ & $\mathbf{1 . 0 0}$ & $\mathbf{0 . 8 9}$ & Auto-WEKA \\
\hline
\end{tabular}

Table 5. Statistical test results of $15 \mathrm{~min}$ Vis forecasts $\leq 1600 \mathrm{~m}$ for the five algorithms (Alg) selected with input from SODAR (source 1), ASWS (source 2) and observer (source 3). The satisfactory algorithm result is in bold.

\begin{tabular}{cccccccccccr}
\hline Alg. & $\begin{array}{c}\text { Input } \\
\text { Data }\end{array}$ & $\begin{array}{c}\text { POD } \\
\text { (YES) }\end{array}$ & $\begin{array}{c}\text { 1-FAR } \\
\text { (YES) }\end{array}$ & $\begin{array}{c}\text { F-M } \\
\text { (YES) }\end{array}$ & $\begin{array}{c}\text { BIAS } \\
\text { (YES) }\end{array}$ & $\begin{array}{c}\text { POD } \\
\text { (NO) }\end{array}$ & $\begin{array}{c}\text { 1-FAR } \\
\text { (NO) }\end{array}$ & $\begin{array}{c}\text { F-M } \\
\text { (NO) }\end{array}$ & $\begin{array}{c}\text { BIAS } \\
\text { (NO) }\end{array}$ & $\begin{array}{c}\text { KAPPA } \\
\text { Configuration }\end{array}$ \\
\hline BN & 2 and 3 & 0.88 & 0.99 & 0.43 & 0.32 & 0.99 & 0.88 & 1.00 & 0.99 & 0.42 & 1 \\
MP & 2 and 3 & 0.68 & 1.00 & 0.78 & 1.34 & 1.00 & 0.68 & 1.00 & 1.00 & 0.78 & 1 \\
RF & 2 and 3 & $\mathbf{0 . 8 8}$ & $\mathbf{1 . 0 0}$ & $\mathbf{0 . 8 9}$ & $\mathbf{1 . 0 2}$ & $\mathbf{1 . 0 0}$ & $\mathbf{0 . 8 8}$ & $\mathbf{1 . 0 0}$ & $\mathbf{1 . 0 0}$ & $\mathbf{0 . 8 9}$ & Auto-WEKA \\
HT & 2 and 3 & 0.56 & 1.00 & 0.67 & 1.50 & 1.00 & 0.56 & 1.00 & 1.00 & 0.67 & 1 \\
RT & $\mathbf{2}$ and 3 & $\mathbf{0 . 8 9}$ & $\mathbf{1 . 0 0}$ & $\mathbf{0 . 8 9}$ & $\mathbf{1 . 0 0}$ & $\mathbf{1 . 0 0}$ & $\mathbf{0 . 8 9}$ & $\mathbf{1 . 0 0}$ & $\mathbf{1 . 0 0}$ & $\mathbf{0 . 8 9}$ & $\mathbf{1}$ \\
RF & $\mathbf{1 , 2}$ and 3 & $\mathbf{0 . 8 9}$ & $\mathbf{1 . 0 0}$ & $\mathbf{0 . 8 9}$ & $\mathbf{1 . 0 0}$ & $\mathbf{1 . 0 0}$ & $\mathbf{0 . 8 9}$ & $\mathbf{1 . 0 0}$ & $\mathbf{1 . 0 0}$ & $\mathbf{0 . 8 9}$ & Auto-WEKA \\
\hline
\end{tabular}

As previously analyzed, Tables 6-8 also shows the best performance algorithms (and those satisfactory algorithms in bold), by visibility limit and $30 \mathrm{~min}$ forecast. It is observed that no algorithm obtained a POD (V) greater than $80 \%$ for the limit of Vis $\leq 3700 \mathrm{~m}$, and there are only three algorithms, i.e., one and two for Vis $\leq 4500$ and Vis $\leq 1600$, respectively, with satisfactory performance. The evaluation statistics suffered a percentage reduction (in parentheses) in relation to the 15 min predictions, as follows: POD (S, N) $(7.53 \%, 0.08 \%)$, 1-FAR (S, N) $(0.08 \%, 7.53 \%)$, F-M (S, N) $(5.28 \%, 0.14 \%)$, BIAS (S, N) $(5.06 \%, 0.06 \%)$, KAPPA $(\mathrm{S}, \mathrm{N})(10.89 \%, 0.008 \%)$. The results of the 45 and $60 \mathrm{~min}$ forecasts deteriorated significantly, and are therefore not discussed. 
Table 6. Statistical test results of $30 \mathrm{~min}$ Vis forecasts $\leq 4500 \mathrm{~m}$ for the five algorithms (Alg) selected with input from SODAR (source 1), ASWS (source 2) and observer (source 3). The satisfactory algorithm result is in bold.

\begin{tabular}{cccccccccccc}
\hline Alg & $\begin{array}{c}\text { Input } \\
\text { Data }\end{array}$ & $\begin{array}{c}\text { POD } \\
\text { (YES) }\end{array}$ & $\begin{array}{c}\text { 1-FAR } \\
\text { (YES) }\end{array}$ & $\begin{array}{c}\text { F-M } \\
\text { (YES) }\end{array}$ & $\begin{array}{c}\text { BIAS } \\
\text { (YES) }\end{array}$ & $\begin{array}{c}\text { POD } \\
\text { (NO) }\end{array}$ & $\begin{array}{c}\text { 1-FAR } \\
\text { (NO) }\end{array}$ & $\begin{array}{c}\text { F-M } \\
\text { (NO) }\end{array}$ & $\begin{array}{c}\text { BIAS } \\
\text { (NO) }\end{array}$ & $\begin{array}{c}\text { KAPPA } \\
\text { Data Set } \\
\text { Configuration }\end{array}$ \\
\hline BN & 2 and 3 & 0.84 & 0.95 & 0.49 & 0.42 & 0.95 & 0.84 & 0.97 & 0.96 & 0.47 & 1 \\
MP & 2 and 3 & 0.75 & 1.00 & 0.80 & 1.15 & 1.00 & 0.75 & 0.99 & 1.00 & 0.79 & 1 \\
RF & $\mathbf{2}$ and 3 & $\mathbf{0 . 8 2}$ & $\mathbf{0 . 9 9}$ & $\mathbf{0 . 8 1}$ & $\mathbf{1 . 0 0}$ & $\mathbf{0 . 9 9}$ & $\mathbf{0 . 8 2}$ & $\mathbf{0 . 9 9}$ & $\mathbf{1 . 0 0}$ & $\mathbf{0 . 8 1}$ & Auto-WEKA \\
HT & 2 and 3 & 0.77 & 0.99 & 0.79 & 1.05 & 0.99 & 0.77 & 0.99 & 1.00 & 0.78 & 1 \\
RT & 2 and 3 & 0.74 & 1.00 & 0.78 & 1.12 & 1.00 & 0.74 & 0.99 & 1.00 & 0.78 & 1 \\
RF & $\mathbf{1}$ 2 and 3 & $\mathbf{0 . 8 2}$ & $\mathbf{1 . 0 0}$ & $\mathbf{0 . 8 7}$ & $\mathbf{1 . 1 3}$ & $\mathbf{1 . 0 0}$ & $\mathbf{0 . 8 2}$ & $\mathbf{1 . 0 0}$ & $\mathbf{1 . 0 0}$ & $\mathbf{0 . 8 7}$ & Auto-WEKA \\
\hline
\end{tabular}

Table 7. Statistical test results of $30 \mathrm{~min}$ Vis forecasts $\leq 3700 \mathrm{~m}$ for the five algorithms (Alg) selected with input from SODAR (source 1), ASWS (source 2) and observer (source 3).

\begin{tabular}{cccccccccccc}
\hline Alg & $\begin{array}{c}\text { Input } \\
\text { Data }\end{array}$ & $\begin{array}{c}\text { POD } \\
\text { (YES) }\end{array}$ & $\begin{array}{c}\text { 1-FAR } \\
\text { (YES) }\end{array}$ & $\begin{array}{c}\text { F-M } \\
\text { (YES) }\end{array}$ & $\begin{array}{c}\text { BIAS } \\
\text { (YES) }\end{array}$ & $\begin{array}{c}\text { POD } \\
\text { (NO) }\end{array}$ & $\begin{array}{c}\text { 1-FAR } \\
\text { (NO) }\end{array}$ & $\begin{array}{c}\text { F-M } \\
\text { (NO) }\end{array}$ & $\begin{array}{c}\text { BIAS } \\
\text { (NO) }\end{array}$ & $\begin{array}{c}\text { KAPPA } \\
\text { Cota Set } \\
\text { Configuration }\end{array}$ \\
\hline BN & 2 and 3 & 0.84 & 0.96 & 0.30 & 0.21 & 0.96 & 0.84 & 0.98 & 0.96 & 0.28 & 1 \\
MP & 2 and 3 & 0.61 & 1.00 & 0.70 & 1.39 & 1.00 & 0.61 & 1.00 & 1.00 & 0.70 & 1 \\
RF & 2 and 3 & 0.75 & 1.00 & 0.77 & 1.05 & 1.00 & 0.75 & 1.00 & 1.00 & 0.76 & 4 \\
HT & 2 and 3 & 0.67 & 0.99 & 0.61 & 0.83 & 0.99 & 0.67 & 1.00 & 1.00 & 0.60 & 1 \\
RT & 2 and 3 & 0.64 & 1.00 & 0.72 & 1.27 & 1.00 & 0.64 & 1.00 & 1.00 & 0.72 & 1 \\
RF & 1 2 and 3 & 0.71 & 1.00 & 0.71 & 1.00 & 1.00 & 0.71 & 1.00 & 1.00 & 0.78 & Auto-WEKA \\
\hline
\end{tabular}

Table 8. Statistical test results of $30 \mathrm{~min}$ Vis forecasts $\leq 1600 \mathrm{~m}$ for the five algorithms (Alg) selected with input from SODAR (source 1), ASWS (source 2) and observer (source 3). The satisfactory algorithm result is in bold.

\begin{tabular}{cccccccccccc}
\hline Alg & $\begin{array}{c}\text { Input } \\
\text { Data }\end{array}$ & $\begin{array}{c}\text { POD } \\
\text { (YES) }\end{array}$ & $\begin{array}{c}\text { 1-FAR } \\
\text { (YES) }\end{array}$ & $\begin{array}{c}\text { F-M } \\
\text { (YES) }\end{array}$ & $\begin{array}{c}\text { BIAS } \\
\text { (YES) }\end{array}$ & $\begin{array}{c}\text { POD } \\
\text { (NO) }\end{array}$ & $\begin{array}{c}\text { 1-FAR } \\
\text { (NO) }\end{array}$ & $\begin{array}{c}\text { F-M } \\
\text { (NO) }\end{array}$ & $\begin{array}{c}\text { BIAS } \\
\text { (NO) }\end{array}$ & $\begin{array}{c}\text { KAPPA } \\
\text { Cota Set } \\
\text { Configuration }\end{array}$ \\
\hline BN & 2 and 3 & 0.81 & 0.99 & 0.32 & 0.24 & 0.99 & 0.81 & 1.00 & 0.99 & 0.31 & 1 \\
MP & 2 and 3 & 0.41 & 1.00 & 0.56 & 2.17 & 1.00 & 0.41 & 1.00 & 1.00 & 0.55 & 1 \\
RF & 2 and 3 & 0.73 & 1.00 & 0.76 & 1.11 & 1.00 & 0.73 & 1.00 & 1.00 & 0.76 & 3 \\
HT & 2 and 3 & 0.17 & 0.94 & 0.02 & 0.05 & 0.94 & 0.17 & 0.97 & 0.94 & 0.01 & 3 \\
RT & 2 and 3 & 0.66 & 0.34 & 0.76 & 1.39 & 1.00 & 1.00 & 1.00 & 1.00 & 0.76 & 1 \\
RF & $\mathbf{1 , 2}$ and 3 & $\mathbf{0 . 8 8}$ & $\mathbf{1 . 0 0}$ & $\mathbf{0 . 9 2}$ & $\mathbf{1 . 1 0}$ & $\mathbf{1 . 0 0}$ & $\mathbf{0 . 8 8}$ & $\mathbf{1 . 0 0}$ & $\mathbf{1 . 0 0}$ & $\mathbf{0 . 7 1}$ & Auto-WEKA \\
\hline
\end{tabular}

\subsection{Visibility Regressive Nowcasting}

Similar to the previous case, the new experiments were run employing regressive algorithms while considering conditions, as follows: (1) the five selected WEKA regressive algorithms; (2) the three visibility thresholds used Vis $=4500,=3700$, and $=1600$ with four prediction times of $15 \mathrm{~min}$ intervals up to $60 \mathrm{~min}$; and (3) two data sets with or without SODAR data, and using Auto-WEKA support. Table 9 shows a summary of the best statistical results for the test experiments with regressive algorithms for all prediction times, and it is noted that RF is the algorithm with the best performance regardless of the input data set or the prediction time considered. All predictions almost perfectly correlated (column 4), which means that the trends of the predicted values follow the behavior of the observations almost perfectly. Figure 4 shows the three thresholds ( \pm MAE) of visibility represented by the black lines and their respective minimum (cross) and maximum (black triangle) errors for better 15, 30, 45, 60 min predictions. Independent of prediction time, variations in visibility predictions for 4500, 3700, and $1600 \mathrm{~m}$ fit into the following ranges (with percentage visibility changes in parentheses): 4148-4852 $\mathrm{m}$ (7.8\%), 3348-4052 m (9.5\%), and 1248-1952 m (22\%), respectively. In short, assuming acceptable error in forecasting of the visibility is about $20 \%$, the results of the predictions with the regressive algorithms were more representative than categorical ones. This is verified using the observations. 
Table 9. Better statistical results of short-term visibility forecast using regressive algorithms and those whose training was performed using the data set with configuration (5), whose records were divided as Auto-WEKA default.

\begin{tabular}{cccccc}
\hline Algorithm & Prediction Time (min) & Input Data Source & CC & MAE (m) & RAE \\
\hline RF & 15 & 1,2 and 3 & 0.99 & 198.58 & 0.04 \\
RF & 15 & 2 and 3 & 0.99 & 189.85 & 0.04 \\
RF & 30 & 1,2 and 3 & 0.99 & 304.86 & 0.06 \\
RF & 30 & 2 and 3 & 0.99 & 291.38 & 0.06 \\
RF & 45 & 1,2 and 3 & 0.99 & 378.70 & 0.08 \\
RF & 45 & 2 and 3 & 0.99 & 351.85 & 0.07 \\
RF & 60 & 1,2 and 3 & 0.99 & 409.32 & 0.08 \\
RF & 60 & 2 and 3 & 0.99 & 343.88 & 0.07 \\
\hline
\end{tabular}

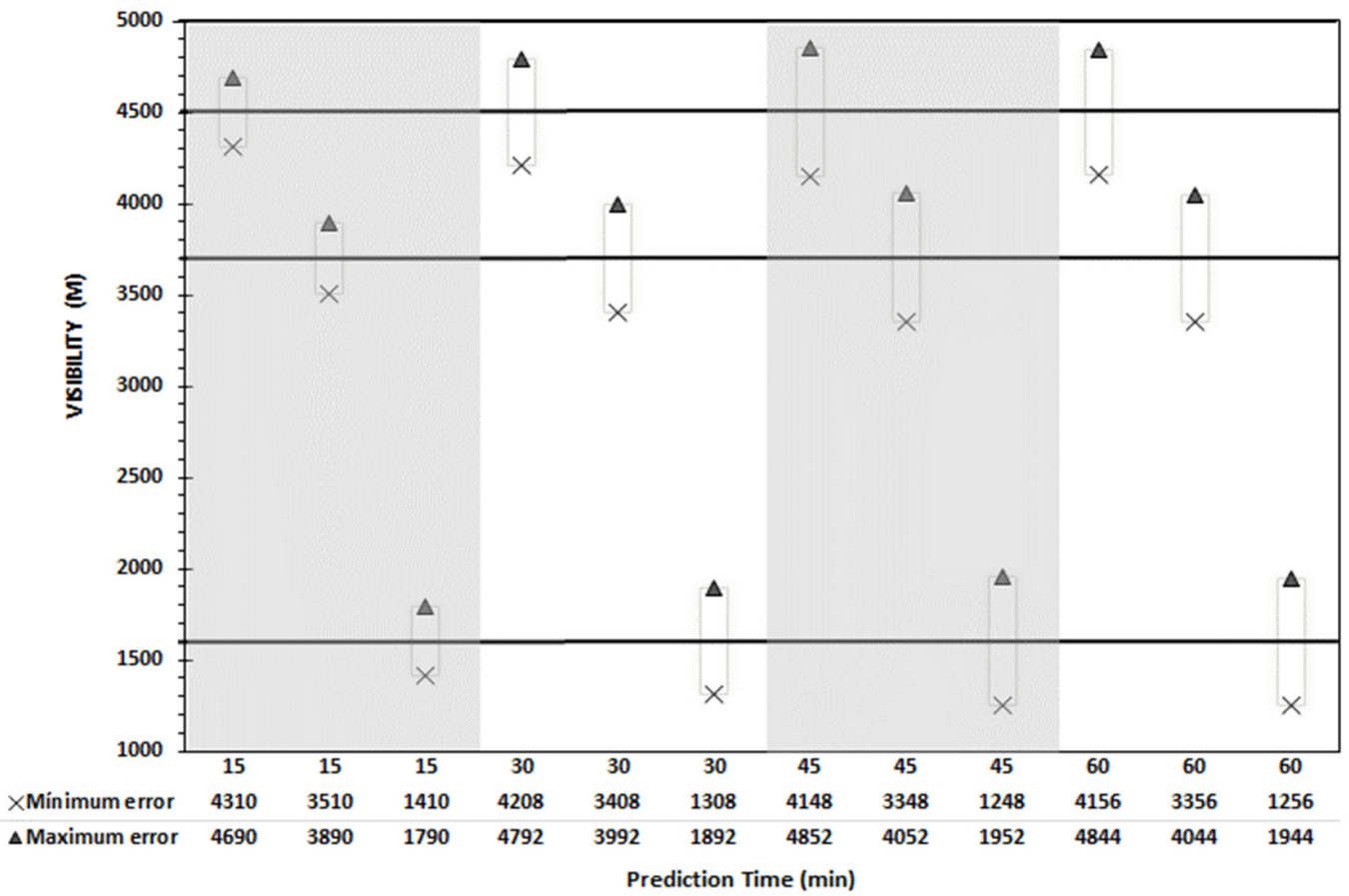

Figure 4. Minimum (cross) and maximum (black triangle) errors for each visibility threshold ( \pm mean absolute error), represented by the horizontal black lines at 4500,3700 , and $1600 \mathrm{~m}$ of the best regressive forecasts of 15, 30, 45, $60 \mathrm{~min}$ in Table 9.

Figure 5 exemplifies the performance of the set of predictions and observations for a low-visibility event that occurred between 5 a.m. and 1 p.m. on 23 June 2009. Regardless of the forecast time, it is noted that the 15,30, 45 and 60 min visibility forecasts followed the behavior of the observation (black line in Figure 5) with all correlation coefficients $>0.95$ and their mean absolute errors $\leq 321 \mathrm{~m}$. This can be verified through the behavior of the predicted visibilities, as they followed the observations almost perfectly; that is, they decreased at 5:45 a.m., remained relatively stable after 8:00 a.m.- when the observed visibility oscillated close to $1000 \mathrm{~m}$-and increased with the increase in observations from 11:45 a.m. Furthermore, the 15, 30, 45, and 60 min forecasts slightly overestimated the observations (based on the mean error of forecast-observation values for each prediction time) by about 146.4, 121.9, 224.2, and $292.1 \mathrm{~m}$, respectively. 


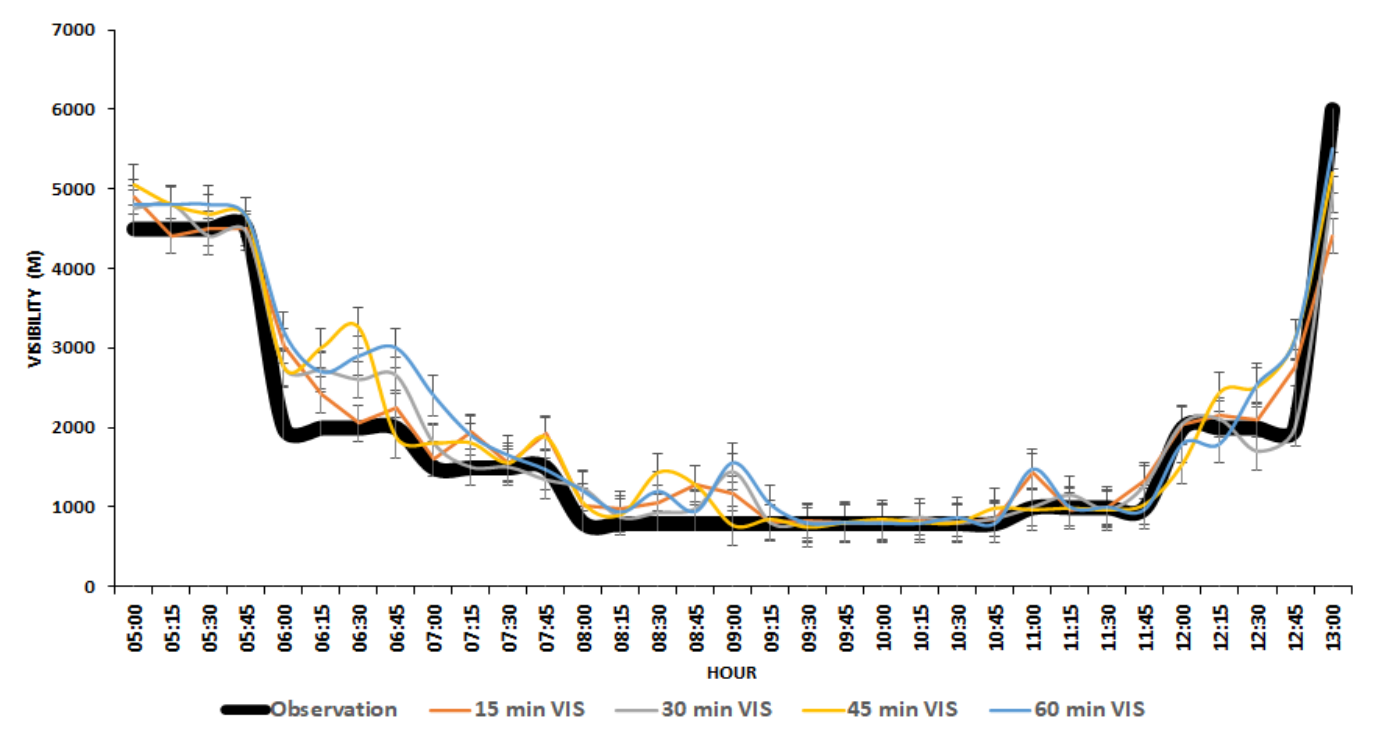

Figure 5. Regressive forecasts of visibilities and observations in the period from 5 a.m. to 1 p.m. on 23 June 2009.

\subsection{Ceiling Nowcasting}

Before presenting the results for forecasting the ceiling and the quantity of clouds, it is important to mention that the SODAR data was collected in the period 2017-2018, and during this period, the ceilometer used, part of the ASWS platform, was inoperative. Thus, training of the algorithms for the ceiling is limited to the 2009-2016 period, and Table 10 is missing data from SODAR. Table 6 shows a summary of the best results for the ceiling test experiments with regressive algorithms for all prediction times. Similar to the visibility results, the RF algorithm also results in the best performance of ceiling forecasts, regardless of the input data set or the prediction time considered. It is also found that the predicted values of $\mathrm{H}_{\mathrm{c}} / \mathrm{C}_{\mathrm{q}}$ of $15,30,45$ and 60 min are highly correlated with the observations, with their values varying in the range of $0.96-0.97$ and $0.77-0.86$, respectively (column 4, Table 10), and the observations are found to be close to the predictions, since the MAE and the RAE for ceiling vary in the ranges from 126.13 to $195.19 \mathrm{ft}$ and 0.10 to $0.16 \mathrm{ft}$, respectively. The results of the three ceiling thresholds (i.e., 1200, 1000, and $300 \mathrm{ft}$ ) can be considered encouraging since they vary approximately within the $\mathrm{H}_{\mathrm{c}}$ ranges from 1005 to $1395 \mathrm{ft}, 805$ to $1195 \mathrm{ft}$, and 105 to $495 \mathrm{ft}$, respectively.

Table 10. Better statistical results of short-term $\mathrm{H}_{c} / \mathrm{C}_{\mathrm{q}}$ forecast using regressive algorithms, whose training was performed using the data set with configuration (5), whose records were divided as Auto-WEKA default.

\begin{tabular}{cccccc}
\hline Algorithm & $\begin{array}{c}\text { Prediction Time } \\
\text { (min) }\end{array}$ & Input Data Source & CC & $\begin{array}{c}\text { MAE } \\
(\mathbf{f t} / \mathbf{o k t a})\end{array}$ & RAE \\
\hline RF & 15 & 2 and 3 & 0.97 & 126.13 feet & 0.1 \\
RF & 15 & 2 and 3 & 0.86 & 0.55 okta & 0.32 \\
RF & 30 & 2 and 3 & 0.97 & 166.02 feet & 0.14 \\
RF & 30 & 2 and 3 & 0.81 & 0.69 okta & 0.4 \\
RF & 45 & 2 and 3 & 0.96 & 182.95 feet & 0.15 \\
RF & 45 & 2 and 3 & 0.83 & 0.63 okta & 0.37 \\
RF & 60 & 2 and 3 & 0.96 & 195.19 feet & 0.16 \\
RF & 60 & 2 and 3 & 0.77 & 0.77 okta & 0.44 \\
\hline
\end{tabular}




\section{Conclusions}

This study proposes a set of objective methods based on ML (using the trained and tested algorithms), with an extremely low computational cost capable of making short-term forecasts of Vis and Hc up to $60 \mathrm{~min}$.

Analysis of historical meteorological data suggested that the weather conditions at any airport can be more impacted by the restriction of visibility than the ceiling, and the critical period of the day is just before sunrise until close to noon during May, June, and July. The results with optimal categorical methods of visibility predictions are satisfactory in $15 \mathrm{~min}$ and have not been successful in any forecast for the ceiling. On the other hand, ceiling and visibility predictions based on regressive methods of up to $60 \mathrm{~min}$ are encouraging, since the values of the metrics with relatively lower biases are quite acceptable.

In summary, following conclusions can be drawn from the present work:

- ML algorithms resulted in up to $20 \%$ better prediction in Vis when regressive techniques were used with a significant amount of reliable data;

- Training data sets need to be improved accurately in temporal and 16 spatial resolutions, and use of data from sensors (visibility meters, ceilometer, etc.) instead of human observations. When sensor observations were used in training, ML algorithms had more accurate Vis and $\mathrm{H}_{\mathrm{c}}$ predictions;

- The $1 \mathrm{~h}$ Vis and $\mathrm{H}_{\mathrm{c}}$ data obtained by observers may not follow the dynamics of some meteorological phenomena, impairing the assertiveness of the method. Furthermore, observations provide a spatial resolution for Vis, which may reduce the efficacy of the algorithm's training compared to continuous sensor based Vis data. It is obvious that the lack of lengthier history series in the SODAR data profiles, the absence of visibility sensor usage, and the ceilometer's inoperability since 2016 were all factors that led to the trained algorithm's performance decline; and

- The ML methods proposed here can identify visibility and ceiling restrictions accurately, thus, they can improve the short-term forecasts of up to $1 \mathrm{~h}$. Thus, the new ML-based methods can be considered an alternative to operational forecasts based on NWP models.

In the future, we intend to use a NWP model to simulate the atmospheric conditions of visibility and ceiling that limits the airport operation, and apply the training and testing of the ML algorithms. Using simulated data and observations, including a long time series of high-frequency data based on SODAR, ceilometer, and automatic weather stations, we will be able to extend the prediction time of visibility and ceiling beyond the one-hour prediction time.

Author Contributions: Conceptualization, G.B.F. and F.L.d.A.N.; methodology, G.B.F.; software, F.M.C.; validation, G.B.F., F.L.d.A.N. and I.G.; formal analysis, F.M.C.; investigation, F.M.C.; resources, F.M.C.; data curation, F.M.C.; writing-original draft preparation, G.B.F.; writing—review and editing, G.B.F., F.L.d.A.N. and I.G.; visualization, F.M.C., G.B.F. and F.L.d.A.N.; supervision, F.L.d.A.N.; project administration, G.B.F.; funding acquisition, G.B.F. All authors have read and agreed to the published version of the manuscript.

Funding: This study is funded by the Department of Airspace Control via the Brazilian Organization for Scientific and Technological Development of Airspace Control (CTCEA) (GRANT: 002-2018/COPPETEC_CTCEA) and Financier of Studies and Projects (FINEP) GRANT: FINEP 01.11.0100.00/FUJB 16.278-7.

Data Availability Statement: The data presented in this study are available on request from the corresponding author. The data are not publicly available due to be proprietary data of the Department of Airspace Control (DECEA) and the Brazilian Airport Infrastructure Company (INFRAERO).

Acknowledgments: The authors are grateful to the DECEA and INFRAERO for providing the data used in this research.

Conflicts of Interest: The authors declare no conflict of interest. 


\section{References}

1. DECEA. Relatório de Performance do Sistema de Controle do Espaço Aéreo Brasileiro (SISCEAB). 2018. Available online: http:/ / especiais.decea.gov.br/performance/wp-content/uploads/2020/08/Rela_SISCEAB_ESTUDO-2_compressed.pdf (accessed on 4 January 2021).

2. Gultepe, I.; Sharman, R.; Williams, P.D.; Zhou, B.; Ellrod, G.; Minnis, P.; Trier, S.; Griffin, S.; Yum, S.S.; Gharabaghi, B.; et al. A review of high impact weather for aviation meteorology. Pure Appl. Geophys. 2019, 176, 1869-1921. [CrossRef]

3. Lima, J.S. Previsão de ocorrências de nevoeiros em Porto Alegre: Método objetivo, São José dos Campos: Instituto de Proteção ao Voo do Ministério da Aeronáutica. Tech. Rep. 1982, 18.

4. Dias, M.A.F.S.; Machado, A.J. The role of local circulations in summertime convective development and nocturnal fog in São Paulo, Brazil. Bound.-Layer Meteorol. 1997, 82, 135-157. [CrossRef]

5. Oliveira, G.A. Método Estatístico no Auxílio à Previsão de Nevoeiro Para o Aeroporto de Guarulhos. Master's Thesis, Federal University of Santa Catarina, Florianópolis, Brazil, 2002. Available online: https://repositorio.ufsc.br/xmlui/bitstream/handle/ 123456789/83415/188292.pdf?sequence=1\&isAllowed=y (accessed on 4 January 2021).

6. França, V.D.J. Avaliação da Metodologia de Previsão de Nevoeiro e Visibilidade Horizontal do Modelo ETA. Master's Thesis, National Institute for Space Research, São José do Campos, Brazil, 2008; p. 172.

7. Fedorova, N.; Levit, V.; Fedorov, D. Fog and stratus formation on the coast of Brazil. Atmos. Res. 2008, 87, 268-278. [CrossRef]

8. Fedorova, N.; Levit, V.; Silva, A.O.; Santos, D.M.B. Low Visibility formation and forecasting on the northern coast of Brazil. Pure Appl. Geophys. 2013, 170, 689-709. [CrossRef]

9. Gultepe, I.; Tardif, R.; Michaelides, S.C.; Cermak, J.; Bott, A.; Bendix, J.; Müller, M.D.; Pagowski, M.; Hansen, B.; Ellrod, G.; et al. Fog research: A review of past achievements and future perspectives. J. Pure Appl. Geophys. 2007, 164, 1121-1159. [CrossRef]

10. Gultepe, I.; Pagowski, M.; Reid, J. Using surface data to validate a satellite based fog detection scheme. J. Weather. Forecast. 2007, 22, 444-456. [CrossRef]

11. Hansen, B. A fuzzy logic-based analog forecasting system for ceiling and visibility. Weather Forecast. 2007, 22, 1319-1330. [CrossRef]

12. Claxton, B.M. Using a neural network to benchmark a diagnostic parameterization: The Met Office's visibility scheme. Q. J. R. Meteorol. Soc. 2008, 134, 1527-1537. [CrossRef]

13. Almeida, M.V. Aplicação de Técnicas de Redes Neurais Artificiais na Previsão de Curtíssimo Prazo da Visibilidade e Teto Para o Aeroporto de Guarulhos-SP. Ph.D. Thesis, Federal University of Rio de Janeiro, Rio de Janeiro, Brazil, 2009. Available online: http:/ / www.coc.ufrj.br/pt/teses-de-doutorado/153-2009/1186-manoel-valdonel-de-almeida (accessed on 4 January 2021).

14. Colabone, R.O.; Ferrari, A.L.; Vecchia., F.A.S.; Tech, A.R.B. Application of artificial neural networks for fog forecast. J. Aerosp. Technol. Manag. 2015, 7, 240-246. [CrossRef]

15. França, G.B.; Almeida, M.V.; Bonnet, S.M.; Neto, F.L.A. Nowcasting model of low wind profile based on neural network using SODAR data at Guarulhos airport. Int. J. Remote Sens. 2018, 39, 2506-2517. [CrossRef]

16. Freitas, J.H.V.; França, G.B.; Menezes, W.F. Convection forecasting using decision tree in Rio de Janeiro metropolitan area. Anuário IGEO 2018, 42, 127-134. [CrossRef]

17. Almeida, V.A.; França, G.B.; Velho, H.F.C. Short-range forecasting system for meteorological convective events in Rio de Janeiro using remote sensing of atmospheric discharges. Int. J. Remote Sens. 2020, 41, 4372-4388. [CrossRef]

18. Platenik, J.E.G.; França, G.B.; Neto, A.V.P.; da Silva, R.M.; de Almeida, V.A. Previsão de Nevoeiro Utilizando Multicritérios Baseados em Simulações do Modelo WRF para o Aeroporto Internacional Afonso Pena. Anuário IGEO 2020, 43, $376-383$. [CrossRef]

19. Zhou, B.; Du, J.; Gultepe, I.; Dimego, G. Forecast of Low Visibility and Fog from NCEP: Current Status and Efforts. Pure Appl. Geophys. 2012, 169, 895-909. [CrossRef]

20. Da Rocha, R.P.; Gonçalves, F.L.T.; Segalin, B. Fog Events and local atmospheric features simulated by regional climate model for the metropolitan area of São Paulo, Brazil. Atmos. Res. 2015, 151, 176-188. [CrossRef]

21. Perini, A.B.; Filho, D.P.P.; Rodrigues, E.S.; Amaral, F.S.; Reichert, R.F.L. Anuário Estatístico Operacional 2018. INFRAERO. 2019. Available online: https://www4.infraero.gov.br/media/677124/anuario_2018.pdf (accessed on 4 January 2021).

22. Bishop, C.M. Pattern Recognition and Machine Learning; Springer: Berlin/Heidelberg, Germany, 2006; ISBN 978-0-387-31073-2.

23. Silva, W.L.; Neto, F.L.A.; França, G.B.; Matschinske, M.R. Conceptual model for runway change procedure in Guarulhos International Airport based on SODAR data. Aeronaut. J. 2016, 120, 725-734. [CrossRef]

24. Almeida, V.A.; França, G.B.; Velho, H.F.C. Data assimilation for nowcasting in the terminal area of Rio de Janeiro. Ciência Nat. 2020, 42, e40. [CrossRef]

25. Witten, I.H.; Frank, E.; Hall, M.A.; Pal, C.J. Data Mining: Practical Machine Learning Tools and Techniques, 4th ed.; Morgan Kaufmann: Sydney, Australia, 2016; ISBN 978-0-12-804291-5.

26. Thornton, C.; Hutter, F.; Hoos, H.H.; Leyton-Brown, K. Auto-WEKA: Combined selection and hyperparameter optimization of classification algorithms. In Proceedings of the 19th ACM SIGKDD International Conference on Knowledge Discovery and Data Mining-KDD '13, Chicago, IL, USA, 11-14 August 2013; pp. 847-855. [CrossRef]

27. Kotthof, L.; Thornton, C.; Hoos, H.H.; Hutter, F.; Leyton-Brown, K. Auto-WEKA 2.0: Automatic model selection and hyperparameter optimization in WEKA. J. Mach. Learn. Res. 2016, 17, 1-5. 
28. Holmes, G.; Donkin, A.; Witten, I.H. WEKA: A machine learning workbench. In Proceedings of the ANZIIS ‘94-Australian New Zealand Intelligent Information Systems Conference, Brisbane, Australia, 29 November-2 December 1994; pp. 357-361. [CrossRef]

29. Wilks, D.S. Statistical Methods in the Atmospheric Sciences, 2nd ed.; Academic Press: London, UK, 2006.

30. Landis, J.R.; Koch, G.G. The Measurement of Observer Agreement for Categorical Data. Biometrics 1977, 33, 159-174. [CrossRef]

31. Breiman, L. Random Forests. Mach. Lang. 2001, 45, 5-32. [CrossRef] 